\title{
Structural Analysis of 5-aminosalicyl- $L$-glutamic Acid, a Colon-specific Prodrug of 5-aminosalicylic Acid, for Colon-specific Deconjugation
}

\author{
Jihye Kim, Jungyoon Kim, Yonghyun Lee, Young Mi Kim ${ }^{\dagger}$ and Yunjin Jung ${ }^{\dagger}$ \\ College of Pharmacy, Pusan National University, Busan, Korea 609-735 \\ (Received June 9, 2010 • Revised July 26, 2010 • Accepted July 27, 2010)
}

\begin{abstract}
In a previous paper, we showed that 5-aminosalicyl- $L$-aspartic acid (5-ASA-Asp) has much greater deconjugation efficiency in the cecal contents than does 5 -aminosalicyl- $L$-glutamic acid (5-ASA-Glu). To explore a reason for ineffective deconjugation of 5-ASA-Glu, structural analysis of the conjugate was performed. Aromatic acyl- $L$-glutamic acid derivatives, $N$-benzoyl-glumatic acid (BA-Glu), $N$-(2-hydroxybenzoyl)-glutamic acid (SA-Glu), $N$-(3-aminobenzoyl)glutamic acid (3-ABA-Glu) and $N$-(4-aminobenzoyl)-glutamic acid (4-ABA-Glu), were prepared and incubated in the cecal contents. The deconjugation rates were compared with that of 5-ASA-Glu. The order of the rates was BA-Glu $\approx 4-\mathrm{ABA}$ Glu $\approx 3$-ABA-Glu $\gg$ SA-Glu $\approx 5$-ASA-Glu. The deconjugation of the aromatic acyl- $L$-glutamic acid derivatives was carried out by enzyme(s) in the cecal contents since the deconjugation did not occur in the autoclaved cecal contents and on incubation with $N$-benzoyl- $D$-glutamic acid. Our data suggest that the 2-hydroxyl group in 5-ASA is ascribed to the poor deconjugation of 5-ASA-Glu in the cecal contents.
\end{abstract}

Key words -5 -aminosalicylic acid, 5-aminosalicyl- $L$-glutamic acid, structural analysis, inflammatory bowel disease, colon specific prodrug

5-aminosalicylic acid (5-ASA) is the mainstay for inducing and maintaining remission in mild to moderate active ulcerative colitis and Crohn's disease (Crotty and Jewell, 1992; Lofberg, 2003). However, 5-ASA itself is not adequate to be used for treatment of inflammatory bowel disease (IBD) because it is absorbed rapidly and extensively through the upper intestine before it reaches the colon (Crotty and Jewell, 1992). In addition, systemically absorbed 5-ASA is reported to induce nephrotic syndrome (Novis, et al., 1988). For this reason, 5-ASA is formulated as sustained-release preparations or prodrugs for colon-specific delivery (Chourasia and Jain, 2003; Sinha and Kumria, 2001).

Delivery of orally administered drugs specifically to the large intestine is highly desirable for the efficient treatment of diseases developed locally at the large intestine such as inflammatory bowel disease and colorectal cancer (Van den Mooter, 2006). Being delivered to the target site with limited systemic absorption, a smaller dose is needed to reach the therapeutic concentration, which subsequently results in reduced side effects and a greater potency (Sinha and Kumria, 2001). To be colon-specific, a prodrug of 5-ASA should be chemically and biochemically stable and non-absorbable in the upper intestine

†Corresponding Author:

Tel : +82-51-510-2807, E-mail : ymikim@pusan.ac.kr

Tel : +82-51-510-2527, E-mail : jungy@pusan.ac.kr

DOI : 10.4333/KPS.2010.40.4.213 so that it could be delivered to the colon in intact form. And the linkage between the drug and the promoiety should be dissociated to liberate the active drug in the colon (Sinha and Kumria, 2001; Sinha and Kumria, 2003).

In our previous report, we synthesized prodrugs for colonspecific delivery of 5-ASA using acidic amino acids like aspartic acid and glutamic acid as a colon specific carrier (Jung, et al., 2001). Our data demonstrate that conjugation of 5-ASA with aspartic acid and glutamic acid confers colon targetability on the conjugates. However, the 5-ASA release efficiency of glutamic acid conjugated 5-ASA (5-ASA-Glu) in the cecal contents was much lower than that of aspartic acid conjugated 5-ASA (5-ASA-Asp) although the structure difference of the two conjugates is one carbon in the amino acids. In order for structural analysis for the low efficiency of 5-ASA release, $\mathrm{N}$ aromatic acyl- $L$-glutamic acid derivatives, $N$-benzoyl- $L$-glumatic acid (BA-Glu), $N$-(2-hydroxybenzoyl)- $L$-glutamic acid (SA-Glu), $N$-(3-aminobenzoyl)- $L$-glutamic acid (3-ABA-Glu), $N$-(4-aminobenzoyl)- $L$-glutamic acid (4-ABA-Glu) and $N$-(2hydroxy 4-aminobenzoyl)- $L$-glutamic acid (glutamic acid conjugated 5-ASA, 5-ASA-Glu) were synthesized and deconjugation efficiency of the derivatives in the cecal contents was examined. 


\section{Materials and Methods}

\section{Materials}

Benzoylchloride, L-glutamic acid diethyl ester hydrochloride, aspirin, $N$-3-nitrobenzoylchloride, $N$-(4-nitrobenzoyl)- $L$ glutamic acid hemihydrate, 5-nitrosalicylic acid (NSA), $N, N$ 'dicyclohexylcarbodiimidazole (DCC), salicylic acid (SA), benzoic acid (BA) and 10\% $\mathrm{Pd} / \mathrm{C}$ were purchased from Sigma Chemical Co. (St. Louis, MO, USA). They were used as received. Solvents for NMR and HPLC were obtained from Merck Inc (Damstadt, Germany). All other chemicals were reagent grade, commercially available products. IR spectra were recorded on a Varian FT-IR spectrophotometer (Agilent Technologies, Palo Alto, CA, USA). 1H-NMR spectra were taken on a Varian AS 500 spectrometer (Agilent Technologies) and the chemical shifts are in ppm downfield from tetramethylsilane. A Parr 4562 pressure reactor (Parr Instrument Company, Moline, IL, USA) was used for catalytic hydrogenation. The HPLC system consisted of Model 305, 306 pumps, a 117 variable UV detector, a Model 234 autoinjector, a Model 805 manometric module, and a Model $811 \mathrm{C}$ dynamic mixer from Gilson (Middleton, WI, USA).

\section{Preparation of Acidic Amino Acid Conjugated 5-ASA}

5-NSA (5 g, $27.3 \mathrm{mmol}$ ) was dissolved in $170 \mathrm{~mL}$ of anhydrous ethyl acetate and DCC (6.2 g, $30.0 \mathrm{mmol})$ was added in portions, with stirring, at $0^{\circ} \mathrm{C}$ for $1 \mathrm{~h}$. To the reaction mixture, $L$-aspartic acid dimethyl ester (4.45 g, $27.3 \mathrm{mmol}$ ) was added, and the mixture was stirred mechanically for $3 \mathrm{~h}$ at $0^{\circ} \mathrm{C}$ and for $72 \mathrm{~h}$ at room temperature. After filtration, the filtrate was evaporated under reduced pressure to remove the solvent. The oily residue was extracted with a saturated solution of $\mathrm{NaHCO}_{3}$. The combined extract was acidified with $3 \mathrm{M} \mathrm{HCl}$, extracted with ethyl acetate, dried with anhydrous $\mathrm{Na}_{2} \mathrm{SO}_{4}$, and the solvent was removed under reduced pressure. The residue was loaded on a silica gel open column and eluted with $\mathrm{CHCl}_{3}$ / $\mathrm{MeOH}$ (100/1.5), from which 5-nitrosalicyl-L-aspartic acid dimethyl ester was obtained $\left[5.1 \mathrm{~g}, 58 \%\right.$ yield; $\mathrm{mp}: 149-150^{\circ} \mathrm{C}$; IR (nujol) umax $(\mathrm{C}=\mathrm{O})$ : 1640, 1725, $1749 \mathrm{~cm}^{-1} ;{ }^{1} \mathrm{H}$ NMR $\left(\mathrm{CDCl}_{3}\right)$ : 2.9-3.2 (2H), $3.7(\mathrm{~s}, 3 \mathrm{H}), 3.8(\mathrm{~s}, 3 \mathrm{H}), 5.0(\mathrm{~m}, 1 \mathrm{H})$, 7.0-8.8 (m, 3H)]. 5-Nitrosalicyl-Lglutamic acid dimethyl ester was obtained by following the same procedure [mp: $75 \pm 77^{\circ} \mathrm{C}$; IR (nujol) umax $(\mathrm{C}=\mathrm{O})$ : 1650, 1717, $1745 \mathrm{~cm}^{-1} ;{ }^{1} \mathrm{H}$ NMR $\left(\mathrm{CDCl}_{3}\right): 2.2(\mathrm{~m}, 2 \mathrm{H}), 2.5(\mathrm{t}, 2 \mathrm{H}), 3.7(\mathrm{~s}, 3 \mathrm{H}), 3.8(\mathrm{~s}, 3 \mathrm{H}), 4.7$ (q, $1 \mathrm{H}), 7.0-8.5(\mathrm{~m}, 3 \mathrm{H})]$. 5-Nitrosalicyl- $L$-aspartic acid dimethyl ester ( $1 \mathrm{~g}, 3.95 \mathrm{mmol}$ ) and $200 \mathrm{mg}$ of $10 \% \mathrm{Pd} / \mathrm{C}$ in methanol $(20 \mathrm{~mL})$ were hydrogenated in a Parr pressure reactor at $50 \mathrm{psi}$ for $1 \mathrm{~h}$. After filltering and removal of methanol, $1 \mathrm{M}$
$\mathrm{NaOH}(30 \mathrm{~mL})$ was added and reacted for $5 \mathrm{~h}$ under nitrogen. On adjustment of $\mathrm{pH}$ to 3-4, 5-ASA-Asp ( $0.58 \mathrm{~g}, 70 \%$ yield) was obtained as white precipitates [mp: $260^{\circ} \mathrm{C}$ (decomp); IR (nujol) umax $(\mathrm{C}=\mathrm{O}): 1640,1690 \mathrm{~cm}^{-1}$; ${ }^{1} \mathrm{H}$ NMR (DMSO-d6): $2.8(\mathrm{~d}, 2 \mathrm{H}), 4.7(\mathrm{q}, 1 \mathrm{H}), 6.0-7.2(\mathrm{~m}, 3 \mathrm{H})] .5-\mathrm{ASA}-\mathrm{Glu}(0.35 \mathrm{~g}$, $38 \%$ yield) was obtained by following the same procedure [mp: $230-232^{\circ} \mathrm{C}$ (decomp); IR (nujol) umax $(\mathrm{C}=\mathrm{O})$ : 1640 , $1731 \mathrm{~cm}^{-1}$; 1H NMR (DMSO-d6): 2.1 (m, 2H), 2.3 (t, 2H), 4.4 $(\mathrm{m}, 1 \mathrm{H}), 6.6-7.5(\mathrm{~m}, 3 \mathrm{H})]$.

\section{Preparation of Aromatic Acyl-L-glutamic Acid deri- vatives}

For synthesis of SA-Glu, to a solution of $1 \mathrm{~g}$ of glutamic acid dimethyl ester hydrochloride in methanol, $1.1 \mathrm{~g}$ of trimethylamine was added slowly and stirred for $2 \mathrm{~h}$ at $0^{\circ} \mathrm{C}$. The reaction mixture was filtered and concentrated to obtain glutamic acid dimethyl ester. $N, N^{\prime}$-dicyclohexylcarbodiimidazole (DCC, $1.1 \mathrm{~g}$ ) was added to a solution of $1 \mathrm{~g}$ of acetylsalicylic acid in $8 \mathrm{~mL}$ of tetrahydrofuran-methylene chloride. Subsequently, glutamic acid dimethyl ester $(0.8 \mathrm{~g})$ was added to the reaction mixture, which was stirred for $3 \mathrm{~h}$ at $0^{\circ} \mathrm{C}$, and left overnight at RT, then filtered. The filtrate was concentrated and was subsequently washed with $5 \% \mathrm{NaHCO}_{3}$ to obtain acetylsalicylic acid-glutamic acid dimethyl ester (AGDE). To AGDE (0.8 g) dissolved in methanol (2 mL), 1M NaOH (10 $\mathrm{ml}$ ) was added and stirred for $1 \mathrm{~h}$ at RT. The reaction mixture subjected to reduced pressure to remove methanol was washed with ether, followed by acidification with $\mathrm{c}-\mathrm{HCl}$ at $0^{\circ} \mathrm{C}$. It was extracted with ethylacetate and the ethylacetate layer was concentrated, which was subjected to recrystallization from ethylacetate-n-hexane to afford the final product $\mathrm{N}-(2-$ hydroxybenzoly)-glutamic acid (Yield: $39 \%$ ) [mp: $163-165^{\circ} \mathrm{C}$, IR (nujol) umax $(\mathrm{C}=\mathrm{O}): 1642,1720 \mathrm{~cm}^{-}{ }^{1}$; ${ }^{1} \mathrm{H}-\mathrm{NMR}$ (DMSOd6): $2.0(\mathrm{~m}, 2 \mathrm{H}), 2.4(\mathrm{t}, 2 \mathrm{H}), 4.2(\mathrm{~m}, 1 \mathrm{H}), 6.5-7.7(\mathrm{~m}, 4 \mathrm{H})]$.

For synthesis of BA-Glu, to the solution of L-glutamic acid $(0.77 \mathrm{~g})$ in $10 \mathrm{~mL}$ of $1 \mathrm{M} \mathrm{NaOH}$, was added benzoylchloride $(0.7 \mathrm{~g})$ and $3 \mathrm{M} \mathrm{NaOH}$ separately from a separating funnel at such a rate that the solution is always slightly alkaline while stirring and cooling below $30^{\circ} \mathrm{C}$. After the addition was complete, the mixture was stirred for $2 \mathrm{~h}$ longer. It was then poured into $3 \mathrm{~mL}$ of $\mathrm{c}-\mathrm{HCl}$. The resulting precipitates were filtered, washed with cold water, dried and recrystallized from ethanolwater. [Yield: $45 \%$, mp: $138^{\circ} \mathrm{C}(\mathrm{dec})$, IR (nujol) ímax $(\mathrm{C}=\mathrm{O})$ : 1645, $1710 \mathrm{~cm}^{-1}$; 1H NMR ( $\left.\mathrm{D}_{2} \mathrm{O}\right): 2.1(\mathrm{~m}, 2 \mathrm{H}), 2.3(\mathrm{t}, 2 \mathrm{H}), 4.0$ (m, 1H), 7.3-7.7 (aromatic H, 5H)]. $N$-benzoyl- $D$-glutamic acid was synthesized as described above.

For synthesis of 3-ABA-Glu, to the solution of L-glutamic acid $(0.77 \mathrm{~g})$ in $10 \mathrm{~mL}$ of $1 \mathrm{M} \mathrm{NaOH}$, was added 3-nitroben- 
Table I. Experimental Conditions of HPLC Analysis for Each Analyte

\begin{tabular}{cccc}
\hline \hline Chemicals & Mobile phase & Column & RT (min) \\
\hline 5-ASA-Asp & $10 \% \mathrm{MeOH} / \mathrm{PB}(\mathrm{pH}$ 6)/TBA $(0.5 \mathrm{mM})$ & Synchropac ODS & 6.4 \\
5-ASA-Glu & $10 \% \mathrm{MeOH} / \mathrm{PB}(\mathrm{pH}$ 6)/TBA $(0.5 \mathrm{mM})$ & Synchropac ODS & 7.8 \\
BA-Glu 5\% & $\mathrm{MeOH} / \mathrm{PB}(\mathrm{pH} 6)$ & Lichrospher 100 RP-18 & 7.1 \\
3-ABA-Glu 5\% & MeOH/PB (pH 6)/TBA $(0.5 \mathrm{mM})$ & Lichrospher 100 RP-18 & 8.1 \\
4-ABA-Glu 5\% & MeOH/PB (pH 6)/TBA $(0.5 \mathrm{mM})$ & Lichrospher 100 RP-18 & 8.6 \\
SA-Glu & Acetic acid/MeOH/Water $(4: 35: 65)$ & Synchropac ODS & 6.3 \\
BA & Acetic acid/MeOH/Water $(4: 35: 65)$ & Synchropac ODS & 14.2 \\
SA & Acetic acid/MeOH/Water $(4: 35: 65)$ & Synchropac ODS & 12.6 \\
\hline
\end{tabular}

*PB: phosphate buffer, TBA: tetrabutylammonium chloride, BA: benzoic acid, SA: salicylic acid, 5-ASA-Asp: aspatic acid conjugated 5aminosalicylic acid, 5-ASA-Glu: glutamic acid conjugated 5-aminosalicylic acid, BA-Glu: $N$-benzoyl- $L$-glutamic acid, 3-3-ABA-Glu: $N$-(3aminobenzoyl)- $L$-glutamic acid, 4-ABA-Glu: $N$-(4-aminobenzoyl)- $L$-glutamic acid

*Flow rate: $1 \mathrm{~mL} / \mathrm{min}$ except for BA-Glu, 3-ABA-Glu and 4-ABA-Glu $(0.7 \mathrm{~mL} / \mathrm{min})$

*Column: Lichrospher 100 RP-18 (250×4.6 mm, $5 \mu \mathrm{m}$, Merck), Synchropac ODS (250×4.6 mm, $5 \mu \mathrm{m}$, Hewlett-Packard)

zoylchloride $(0.93 \mathrm{~g})$ and $3 \mathrm{M} \mathrm{NaOH}$ separately from a separating funnel at such a rate that the solution is always slightly alkaline while stirring and cooling below $30^{\circ} \mathrm{C}$. After the addition was complete, the mixture was stirred for $2 \mathrm{~h}$ longer. It was then poured into $3 \mathrm{ml}$ of $\mathrm{c}-\mathrm{HCl}$. The resulting precipitates were filtered, washed with cold water, dried and recrystallized from ethanol-water. The recrystallized $N$-(3-nitrobenzoyl)- $L$ glutamic acid $(0.5 \mathrm{~g})$ was dissolved in $20 \mathrm{~mL}$ of methanol, added $0.2 \mathrm{~g}$ of $10 \% \mathrm{Pd} / \mathrm{C}$ and hydrogenated in a Parr pressure reactor at $50 \mathrm{psi}$ for $1 \mathrm{~h}$. After filtering and removal of methanol, the residue was added to excess ether to precipitate 3ABA-Glu. [Yield: $32 \%$, mp: $157^{\circ} \mathrm{C}$ (dec), IR (nujol) umax $(\mathrm{C}=\mathrm{O}): 1650,1712 \mathrm{~cm}^{-1}$; $1 \mathrm{H} \mathrm{NMR}\left(\mathrm{D}_{2} \mathrm{O}\right): 2.0(\mathrm{~m}, 2 \mathrm{H}), 2.5(\mathrm{t}$, 2H), $3.8(\mathrm{~m}, 1 \mathrm{H})$, 7.1-7.9 (aromatic $\mathrm{H}, 4 \mathrm{H})]$.

For synthesis of 4-ABA-Glu, $N$-(4-nitrobenzoyl)- $L$-glutamic acid hemihydrate $(0.5 \mathrm{~g})$ was dissolved in $20 \mathrm{~mL}$ of methanol, added $0.2 \mathrm{~g}$ of $10 \% \mathrm{Pd} / \mathrm{C}$ and hydrogenated in a Parr pressure reactor at $50 \mathrm{psi}$ for $1 \mathrm{~h}$. After filtering and removal of methanol, the residue was added to excess ether to precipitate 4ABA-Glu. [Yield: $58 \%, \mathrm{mp}: 174^{\circ} \mathrm{C}$, IR (nujol) umax $(\mathrm{C}=\mathrm{O})$ : 1650, $1724 \mathrm{~cm}^{-1}$; 1H NMR ( $\left.\mathrm{D}_{2} \mathrm{O}\right): 2.2$ (m, 2H), 2.5 (t, 2H), 4.1 (m, 1H), 7.1-7.7 (aromatic H, 5H)].

\section{HPLC Analysis}

Standard solutions of benzoic acid, salicylic acid, 5-aminosalicylic acid, acidic amino acid conjugated 5-ASA and aromatic acyl- $L$-glutamic acid derivatives at appropriate concentrations in the autoclaved cecal contents were prepared by the processes reported previously (Jung, et al., 2000). Briefly, $\mathrm{MeOH}$ $(0.9 \mathrm{~mL})$ was added to the standard solutions $(0.1 \mathrm{~mL}, 2 \mu \mathrm{M}$ $-50 \mu \mathrm{M})$ and mixed on a vortex mixer for $2 \mathrm{~min}$, centrifuged at 14,000 rpm (Eppendorf Centrifuge 5415C, Hamburg, Ger- man) for $5 \mathrm{~min}$ and filtered through a membrane filter $(0.45$ $\mathrm{mm})$. HPLC separation was conducted in the conditions described in the Table I. The eluate was monitored at 224 or $254 \mathrm{~nm}$ by an UV detector measuring the absorption with a sensitivity of AUFS 0.01 . The retention times of analytes were shown in the Table I.

\section{Incubation of Analytes with the Cecal Contents of Rats}

A male Sprague-Dawley rat (200-250 g, Samtako, Kyung Ki-Do, Korea) was anesthetized by diethyl ether and a midline incision was made. The cecal segment of the intestine was cut open and the contents were collected in a glove box, which was previously displaced by nitrogen. Solutions of analytes (1 mmole equivalent of 5-ASA, SA, BA or 4 or 3-ABA/0.9 mL) in $\mathrm{pH} 6.8$ isotonic phosphate buffer $(0.9 \mathrm{~mL})$ and the gut contents $(0.1 \mathrm{~g})$ were placed in a microtube and incubated under nitrogen at $37^{\circ} \mathrm{C}$. At appropriate time intervals, a sample was taken out, centrifuged at 5,000 rpm for $3 \mathrm{~min}$. Methanol (0.9 $\mathrm{mL})$ was added to the supernatant $(0.1 \mathrm{~mL})$ to precipitate the protein, vortexed for $2 \mathrm{~min}$ and centrifuged for $5 \mathrm{~min}$ at 14,000 $\mathrm{rpm}$. The amount of analytes in a $20 \mathrm{~mL}$ portion of the supernatant was determined by HPLC.

\section{Results}

5-aminosalicyl-L-glutamic Acid is Deconjugated Less efficiently in the Cecal Contents than is 5-aminosalicyl$L$-aspartic Acid

We previously reported that aspartic acid but not glutamic acid is a good colon specific carrier for colonic delivery of 5ASA. To ensure the difference of the acidic amino acid con- 
jugated 5-ASA, the 5-ASA conjugates were incubated with the 5,10 and $20 \%$ cecal contents suspension. As shown in Fig $1 \mathrm{~A}$ and $\mathrm{B}$, while the acidic amino acid conjugated 5-ASA was deconjugated to liberate 5-ASA, which was accelerated as the concentration of ceccal contents increased, the 5-ASA release efficiency was much greater for 5-ASA-Asp than for 5-ASAGlu, which is consistent with previous results (Jung, et al., 2001).

The Colonic Degradation of Aromatic Acyl-L-glutamic Acid Derivatives Depends on the Structure of the Aromatic Acyl Moiety

To explore why 5-ASA-Glu had such a low efficiency of colonic activation, aromatic acyl- $L$-glutamic acid derivatives,

A

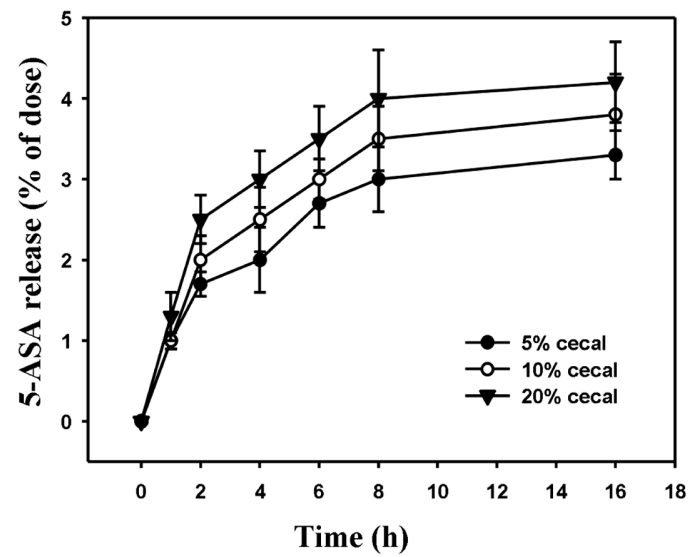

$N$-benzoyl- $L$-glutamic acid (BA-Glu), $N$-(2-hydroxybenzoyl)$L$-glutamic acid (SA-Glu), $N$-(3-aminobenzoyl)- $L$-glutamic acid (3-ABA-Glu) and $N$-(4-aminobenzoyl)- $L$-glutamic acid (4-ABA-Glu), were prepared (Fig. 2) and degradation efficiency of the derivatives was compared with 5-ASA-Glu in the $10 \%$ cecal contents. As shown in Fig. 3, while BA-Glu, 3ABA-Glu and 4-ABA-Glu were degraded effectively, SA-Glu was relatively resistant to the degradation in the cecal contents, which occurred at a comparable rate with degradation of 5ASA-Glu. To rule out a possibility that the differential degradation of the derivatives was due to the various chemical stability of the conjugates in the cecal contents, the cecal contents was sterilized at $121^{\circ} \mathrm{C}$ for 20 min using an autoclave, which is an effective way to inactivate colonic bacterial enzymes

B

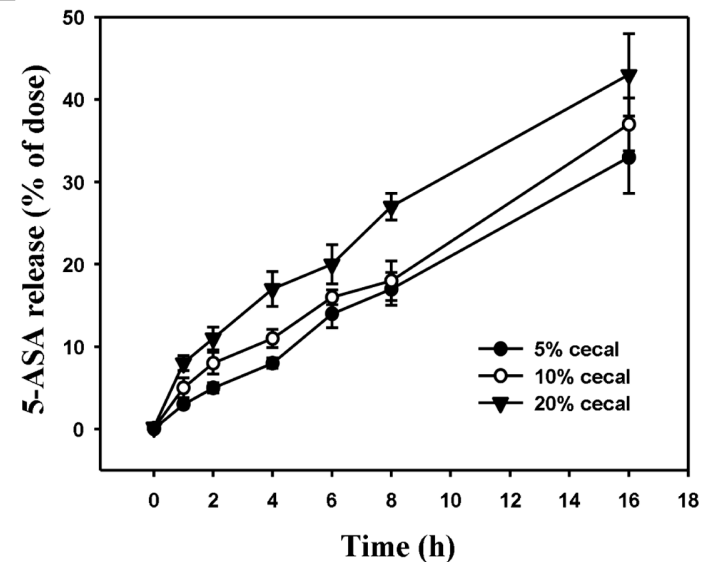

Figure 1. Deconjugation of glutamic acid conjugated 5-aminosalicylic acid (5-ASA-Glu) (A) and aspartic acid conjugated 5-aminosalicylic acid (5-ASA-Asp) (B) in the 5,10 and $20 \%$ cecal contents of SD rats, Data are mean \pm S.E. $(n=3)$.<smiles>O=C(O)CCCC(C(=O)O)c1ccccc1</smiles><smiles>COC(C)(C)C(C)(C)CCCC(=O)c1cccc(N)c1</smiles>

BA-Glu<smiles>Nc1ccc(O)c(C(=O)CCC(=O)O)c1</smiles>
3-ABA-Glu<smiles>O=C(O)CCCC(C(=O)O)c1ccccc1O</smiles>

SA-Glu

\section{5-ASA-Glu}<smiles>Nc1ccc(C(=O)CCCC(=O)O)cc1</smiles>

4-ABA-Glu

Figure 2. Chemical structures of aromatic acyl- $L$-glutamic acid derivatives; $N$-benzoyl- $L$-glutamic acid (BA-Glu), $N$-(2-hydroxybenzoyl)$L$-glutamic acid (SA-Glu), $N$-(3-aminobenzoyl)- $L$-glutamic acid (3-ABA-Glu), $N$-(4-aminobenzoyl)- $L$-glutamic acid (4-ABA-Glu) and 5aminosalicyl- $L$-glutamic acid (5-ASA-Glu). 


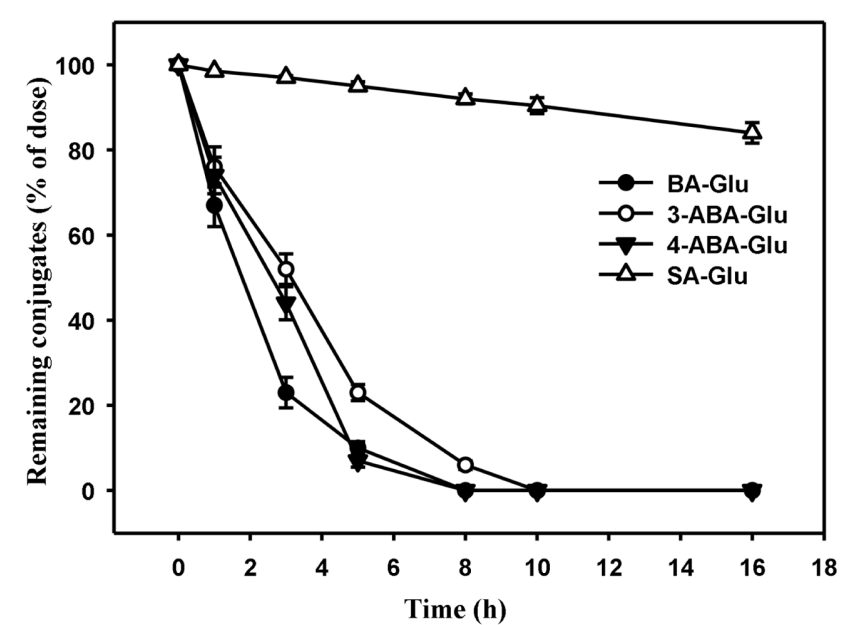

Figure 3. Degradation profiles during incubation of aromatic acyl$L$-glutamic acid derivatives (equiv. to 1 mmole of BA, SA, 3-ABA and $4-\mathrm{ABA}$ ) with the $10 \%$ cecal contents of rats at $37^{\circ} \mathrm{C}$. Data are mean \pm S.E. $(n=3)$.

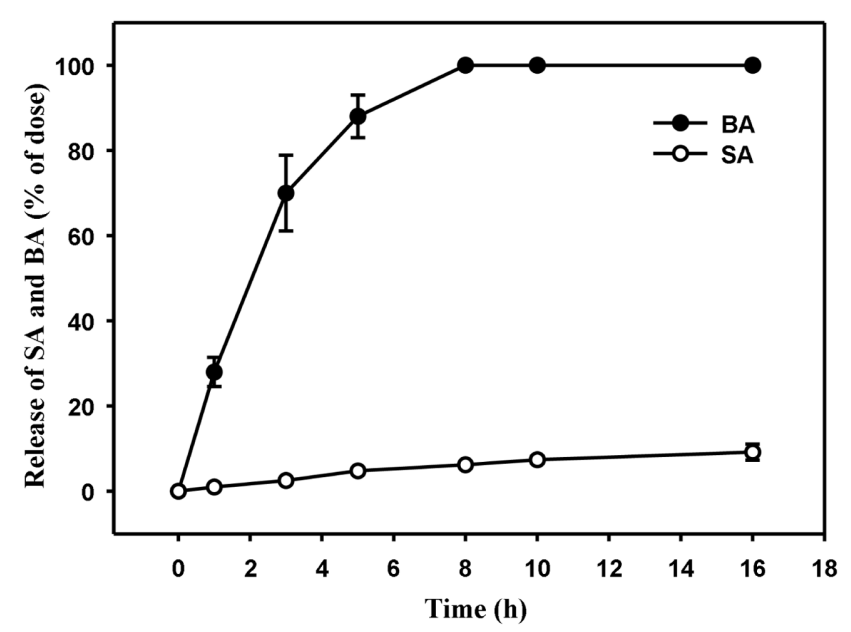

Figure 4. Release profiles of benzoic acid (BA) and salicylic acid (SA) during incubation of BA-Glu and SA-Glu (equiv. to 1 mmole of BA and SA) with the $10 \%$ cecal contents of rats at $37^{\circ} \mathrm{C}$. Data are mean \pm S.E. $(n=3)$.

(Kim, et al., 2005), and the derivatives were incubated with the autoclaved cecal contents. No degradation of the derivatives was detected. To confirm an involvement of a colonic enzyme in the degradation of the derivatives, $N$-benzoyl- $D$-glutamic acid was incubated with the cecal contents. No degradation of $D$-glutamic acid conjugated benzoic acid was observed (data not shown). Finally, we examined whether the colonic degradation presented the deconjugation of the glutamic acid conjugated aromatic acyl compounds. BA-Glu and SA-Glu were incubated with the $10 \%$ cecal contents and liberation of BA and SA from the conjugates was detected. As shown in Fig. 4, during incubation of BA-Glu and SA-Glu, BA and SA were produced as much as the derivatives disappeared as in Fig. 3.
Much greater amount of BA was generated than SA, which was consistent with the colonic degradation efficiency of each conjugate. These results suggest that disappearance of the derivatives in the cecal contents occurred by the deconjugation of the glutamic acid moiety from aromatic acyl- $L$-glutamic acid derivatives. Taken together, our data suggest that the 2hydroxyl group in 5-ASA deters efficient enzymatic deconjugation of 5-ASA-Glu in the cecal contents.

\section{Discussion}

In this report, we demonstrated that SA-Glu of the aromatic acyl- $L$ - glutamic acid derivatives presented the lowest deconjugation efficiency in the cecal contents, the extent of which is similar to 5-ASA-Glu.

5-ASA-Asp and 5-ASA-Glu have differential deconjugation efficiency in the cecal contents as shown in the data demonstrating that degradation of the conjugates and generation of 5-ASA in the cecal contents was much greater for 5-ASA-Asp than for 5-ASA-Glu, which is consistent with a previous report (Jung, et al., 2001). It seems that the low deconjugation of 5ASA-Glu to 5-ASA is attributed to the steric hindrance of the hydroxyl group at the ortho position of the amide linkage between 5-ASA and glutamic acid. This argument is supported by the observation that while BA-Glu, 3-ABA-Glu and 4ABA-Glu without ortho hydroxyl group showed complete degradation in $8 \mathrm{~h}$, SA-Glu with ortho hydroxyl group was degraded up to $7.5 \%$ of the dose, which is a little greater than is 5-ASA-Glu. Our data showing that there was no degradation in the autoclaved cecal contents, rule out a possibility that the different degradation efficiencies of aromatic acyl- $L$-glutamic acid derivatives is due to chemical stability of them. This notion is further confirmed by the data showing that, unlike BA-Glu, $N$-benzoyl- $D$-glutamic acid was resistant to the degradation in the cecal contents. In addition, degradation of aromatic acyl- $L$-glutamic acid derivatives in the cecal contents took place at the amide linkage between glutamic acid and aromatic acids, which is an identical metabolism with that of 5ASA-Glu. Although we do not absolutely exclude a possibility that the metabolic enzyme(s) for 5-ASA-Glu are different from that/those for aromatic acyl- $L$-glutamic acid derivatives, our data suggest that the 2-hydroxyl group in 5-ASA prevented the efficient deconjugation of 5-ASA-Glu in the cecal contents.

\section{Acknowledgements}

This work was supported for two years by Pusan National University Research Grant. 


\section{References}

Chourasia, M.K., Jain, S.K., 2003. Pharmaceutical approaches to colon targeted drug delivery systems, J Pharm Pharmaceut Sci 6(1), 33-66.

Crotty, B., Jewell, D.P., 1992. Drug therapy of ulcerative colitis, $\mathrm{Br}$ J Clin Pharmacol. 34(3), 189-198.

Jung, Y.J., Lee, J.S., Kim, Y.M., 2001. Colon-specific prodrugs of 5-aminosalicylic acid: synthesis and in vitro/in vivo properties of acidic amino acid derivatives of 5-aminosalicylic acid, $\mathrm{J}$ Pharm Sci. 90(11), 1767-1775.

Jung, Y.J., Lee, J.S., Kim, Y.M., 2000. Synthesis and in vitro/in vivo evaluation of 5-aminosalicyl-glycine as a colon-specific prodrug of 5-aminosalicylic acid, J Pharm Sci. 89(5), 594-602.

Kim, H., Kong, H., Choi, B., Yang, Y., Kim, Y., Lim, M.J., Neckers, L., Jung, Y., 2005. Metabolic and pharmacological prop- erties of rutin, a dietary quercetin glycoside, for treatment of inflammatory bowel disease, Pharm Res. 22(9), 1499-1509.

Lofberg, R., 2003. Review article: medical treatment of mild to moderately active Crohn's disease, Aliment Pharmacol Ther. 17 Suppl 2 18-22.

Novis, B.H., Korzets, Z., Chen, P., Bernheim, J., 1988. Nephrotic syndrome after treatment with 5-aminosalicylic acid, Br Med J (Clin Res Ed). 296(6634), 1442.

Sinha, V.R., Kumria, R., 2001. Polysaccharides in colon-specific drug delivery, Int J Pharm. 224(1-2), 19-38.

Sinha, V.R., Kumria, R., 2001. Colonic drug delivery: prodrug approach, Pharm Res. 18(5), 557-564.

Sinha, V.R., Kumria, R., 2003. Microbially triggered drug delivery to the colon, Eur J Pharm Sci. 18(1), 3-18.

Van den Mooter, G., 2006. Colon drug delivery, Expert Opin Drug Deliv. 3(1), 111-125. 